\title{
Trolls e Jornalismo no Twitter
}

Gabriela da SiLVA Zago

Universidade Federal do Rio Grande do Sul - gabrielaz@gmail.com Doutoranda do Programa de Pós-Graduação em Comunicação e Informação da Universidade Federal do Rio Grande do Sul (PPGCOM/UFRGS). Bolsista CAPES.

\begin{abstract}
Resumo
$\mathrm{Na}$ internet, costuma-se utilizar o termo 'troll para designar um indivíduo que perturba o bom andamento de uma comunidade virtual através da postagem de mensagens negativas ou fora de contexto. O trabalho promove uma discussão acerca dos trolls no contexto das etapas do processo jornalístico no Twitter, buscando identificar situações em que interagentes atrapalharam jornais e jornalistas em sua atuação jornalística, como ao repassar informações falsas, ou ao enviar comentários irônicos acerca dos acontecimentos.
\end{abstract}

\section{Palavras-chave}

Jornalismo.Twitter. trolls.

\begin{abstract}
On the internet, we usually use the term 'troll' to designate an individual that disrupts the smooth running of a virtual community by posting negative or out of context messages. The paper promotes a discussion on trolls in the context of the stages of the journalistic process on Twitter, trying to identify situations where interactants disturbed newspapers and journalists in his journalistic procedure, such as by passing on false information, or by sending ironic comments about news events.
\end{abstract}

\section{Keywords}

Journalism. Twitter. Trolls.

Artigo recebido em 16/03/2012

Aprovado em 28/04/2012 


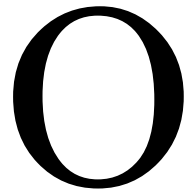

jornalismo contemporâneo exige mais que a mera produção de notícias para um único veículo. Além de produção para múltiplas plataformas, o consumidor de notícias contemporâneo exige cada vez mais que o jornalismo seja interativo, conversacional e participativo.

Diante desse cenário, as organizações jornalísticas passam a criar perfis em sites de redes sociais (para estar onde as pessoas estão e levar a elas seus conteúdos), buscando não só disseminar notícias como também estabelecer uma conversação com seu público.

Embora inúmeros trabalhos exaltem a interatividade como característica do jornalismo (MIELNICZUK, 2003; BELOCHIO, 2009), poucos se detém aos problemas inerentes a essa excessiva cultura da participação (KEEN, 2009; TRÄSEL, 2007; AMARAL; QUADROS, 2006).

$\mathrm{Na}$ internet, o termo 'troll' costuma ser utilizado em blogs e em fóruns de discussão para designar um indivíduo que perturba o bom andamento de uma comunidade virtual através da postagem de mensagens negativas ou fora de contexto. Apesar de se exaltar a participação e a interatividade no jornalismo, trolls também são frequentes no jornalismo.

Com base nesse contexto, o artigo se propõe a discutir a presença de trolls no contexto das etapas do processo jornalístico em um site de redes sociais específico, o Twitter. Em um primeiro momento, discutem-se as origens e principais manifestações dos trolls na internet. A seguir, aborda-se o processo jornalístico em relação aos sites de redes sociais. Logo após, apresenta-se uma discussão sobre os trolls no Twitter a partir de exemplos ilustrativos da prática, recolhidos diretamente na ferramenta.

\section{Trolls: Origens e Principais Manifestações}

O termo troll é utilizado na internet para designar um indivíduo que busca interferir no bom andamento de uma discussão em uma determinada comunidade online, através da postagem de comentários maldosos ou fora de contexto. O comportamento padrão de um troll envolve postar uma mensagem, geralmente em resposta a uma questão, buscando insultar, chatear ou perturbar o grupo. O termo surgiu 
na Usenet ${ }^{\mathrm{i}}$, a partir da expressão trolling for suckers (em português, "lançando a isca para os trouxas").

Os trolls também podem ser considerados uma subcultura típica da internet, na medida em que existem "diversos grupos que se organizam coletivamente para incentivarem a prática de trolling e flaming através do que eles chamam de 'anarquização' da rede" (AMARAL; QUADROS, 2006, online)

A figura dos trolls esteve inicialmente associada a comunidades virtuais, como fóruns, grupos e Usenet. Um exemplo é o Grandpa Wiggly no Reddit (BERGSTROM, 2011), personagem criado por um usuário do site que representava um avô que se engajava ativamente em discussões no Reddit, porém sem que os outros usuários soubessem que se tratava de um personagem.

O troll geralmente age através do uso de pseudônimo, identidade falsa, promovendo o espalhamento de informação falsa ou através da postagem de comentários negativos buscando incitar reação. Para Donath (1999), a identidade falsa está na essência do troll: "trollar é um jogo de falsa identidade, embora seja jogado sem o consentimento da maioria dos jogadores" (DONATH, 1999, online) $)^{\mathrm{ii}}$.

Qualquer comunidade virtual está sujeita à ação de trolls. "Eles postam mensagens agressivas que variam entre a ironia e o humor até ameaças à integridade dos participantes e insultos, especulações a respeito da vida pessoal, palavrões etc." (AMARAL; QUADROS, 2006, online).

Entretanto, não é em todos os ambientes que o troll constitui um personagem malvado a ser combatido. Em sua pesquisa sobre os canais /b/ do 4chan, Fontanella (2010) afirma que, nesse contexto, os trolls são uma espécie de heróis, na medida em que tais espaços são tidos como ambientes liberados do senso comum e do politicamente correto.

É comum a ideia de que o troll nunca faz uma ação única. Ele sempre volta: para medir a repercussão, para continuar a discussão, para aumentar a disseminação. Nesse sentido, "Responder a um troll é muito tentador, especialmente na medida em que essas postagens são feitas para incitar" (DONATH, 1999, online) ${ }^{\mathrm{iii}}$. Assim, impera na internet 
a máxima de que não se deve alimentar os trolls, pois isso pode levar a uma discussão sem fim e a uma visibilidade indesejada à fala do troll.

No Twitter, um comportamento típico de troll está presente na figura do indivíduo que vive pedindo para ser retuitado, ou para ser seguido de volta, atitudes consideradas ruins na ferramenta. Alguns exemplos desses tweets podem ser vistos:

\section{@radiojovempan Por favor..ajuda? Assina ae *-*! NX Zero em Londrina - PR twitition.com/xha4k RT ? \\ Aeww@marcosmion pedeee paa me \#SeGUI tbm que @SIGODEVOLTA}

Gente me segue,que eu sigo de volta!

No primeiro exemplo, o fã de um grupo musical pede ajuda a uma emissora de rádio, na forma de um retweet, para divulgar uma petição. No segundo exemplo, o interagente pede que o apresentador Marcos Mion o siga, prometendo segui-lo de volta. No terceiro, o interagente dirige-se a todos, publicamente, prometendo seguir de volta quem segui-lo.

O conceito de troll também pode ser apropriado para se referir aos interagentes que buscam perturbar o processo jornalístico ao postar mensagens falsas ou excessivamente críticas direcionadas a veículos jornalísticos.

\section{Processo jornalístico em sites de redes sociais}

Sites de redes sociais são serviços da web que permitem aos seus usuários: construir um perfil público, articular uma lista de conexões e visualizar as conexões entre os atores (BOYD; ELLISON, 2007). A principal característica é tornar visíveis as conexões entre os atores. Constituem-se, assim, em espaços em que é possível constituir e manter redes sociais (RECUERO, 2009), ou seja, estabelecer relações entre atores sociais.

Para Boyd (2007), os sites de redes sociais seriam espaços públicos mediados caracterizados por: persistência, buscabilidade, replicabilidade e audiências invisíveis 
(BOYD, 2007). Assim, nos sites de redes sociais as informações ficam visíveis e podem ser rastreadas, o que permite recuperar e conectar informações. A difusão e a replicação de informações nas redes sociais ocorrem porque as redes de contato são diferentes: faz sentido reblogar ou retuitar uma informação. Por essas informações serem difundidas, elas estão suscetíveis a audiências invisíveis, ou seja, podem ser lidas por pessoas desconhecidas do autor da mensagem, para além dos contatos pessoais de um indivíduo.

Desse modo, trolls também podem estar presentes em sites de redes sociais. Esses indivíduos podem enviar mensagens diversas, direcionadas a outros indivíduos ou a organizações que possuam perfis nesses espaços. As mensagens, voltadas para desestabilizar uma determinada discussão, podem receber graus variados de visibilidade. Assim, a presença dos trolls nos sites de redes sociais traz especificidades. Uma dessas especificidades diz respeito ao contexto, que não é dado a priori: o contexto é construído a partir das mensagens trocadas entre os interagentes, nem sempre há tópicos organizados, como em fóruns e comunidades virtuais. Outra especificidade diz respeito à rapidez em que as informações se propagam em sites de redes sociais como o Twitter, o que facilita a visibilidade das mensagens ao mesmo tempo em que dificulta o rastreamento da ação de um troll.

No contexto do jornalismo, sites de redes sociais representam em especial a possibilidade de explorar a característica da interatividade no jornalismo (PALACIOS, 2003), tanto entre jornalistas e público quanto entre leitores. No Twitter, mensagens públicas (reply) e privadas (direct messages) podem ser trocadas entre os perfis, o que pode ser utilizado como um canal para a interação dos veículos com seus públicos.

Os sites de redes sociais podem influenciar em todas as etapas do processo jornalístico, quais sejam, apuração, produção, circulação e consumo (MACHADO; PALACIOS, 2007). Através das redes sociais, os trolls no jornalismo podem, assim, contribuir para o espalhamento de notícias falsas (circulação), enviar informações deliberadamente falsas para jornais (apuração), fazer críticas infundadas ao veículo ou a suas notícias (consumo), entre outras atividades. No site do jornal, é possível usar de mecanismos como moderação de comentários em fóruns e comunidades, o que 
contribui para filtrar a ação dos trolls. Mas como fazer nas redes sociais, em que não se tem controle sobre aquilo que é dito pelos interagentes em seus próprios perfis?

Em um contexto de jornalismo em rede (HEINRICH, 2011), vários nós produzem e disseminam informações, não só jornalistas e jornais. Têm-se, também, blogs, mídia alternativa, jornalistas cidadãos e conteúdos gerados pelo consumidor disputando a atenção dos interagentes na web. Heinrich (2011) fala que os usuários são cada vez mais ativos, não só consumidores de informações: eles também comentam, recomendam, postam links, dentre outras atividades. Cada vez mais o leitor passa a exigir que o jornalismo seja mais interativo, mais conversacional. Saber lidar com essa conversação em rede passa a ser uma das tarefas do jornalista:

A facilitação da conversação com os usuários e a inclusão de recursos de interatividade tem se tornado uma parte inevitável da produção jornalística na esfera em desenvolvimento do jornalismo em rede e como lidar com essas conversações online é apenas uma das tarefas emergentes com as quais as organizações jornalísticas precisam aprender a lidar (HEINRICH, 2011, p. 179)v .

Nesse contexto, aprender a lidar com os trolls nos sites de redes sociais ambientes eminentemente conversacionais - passa a ser tarefa da organização jornalística. Mais do que isso: os trolls também afetam a mídia alternativa, não só a mídia tradicional. Em entrevista concedida a Henrich (2011, p. 179), um participante do Indymedia (no Brasil, Centro de Mídia Independente) comenta que "pelo menos no universo do Indymedia, interatividade significa lidar com trolls! Lidar com desestabilizadores" vi.

Mas como os trolls podem se manifestar nos sites de redes sociais? Como o jornalismo pode lidar com eles? Observar práticas de uso em um site específico pode ajudar a compreender tais manifestações.

\section{Exemplos de acontecimentos e trollagens}

Com o objetivo de ilustrar a discussão acerca dos trolls no contexto das etapas do processo jornalístico no Twitter, buscou-se identificar situações em que interagentes atrapalharam jornais e jornalistas em sua atuação jornalística, como ao repassar informações falsas, ou ao enviar comentários irônicos acerca dos acontecimentos. Os 
exemplos aqui reunidos foram obtidos através de diferentes materiais de pesquisa e servem de ilustração à prática de trollagem jornalística em sites de redes sociais. Optouse por centrar a pesquisa no Twitter por conta de suas características peculiares de funcionamento (limite de 140 caracteres, mensagens postadas no perfil de cada usuário, possibilidade de enviar e receber mensagens públicas através de menções, e particularidades da busca, que apenas armazena as atualizações mais recentes).

Embora o tipo de trollagem mais comumente abordada seja do interagente para o veículo (como ao sugerir uma pauta falsa, ou enviar um comentário ofensivo em resposta a uma notícia), é possível também que ela ocorra entre interagentes (como ao usar humor para comentar acontecimentos jornalísticos), do veículo para o interagente (como ao divulgar notícias falsas) e também entre veículos (quando uma notícia falsa se espalha e é também publicada por outros veículos).

A trollagem interagente-veículo talvez seja aquela que mais interfira no processo jornalístico. Ao sugerir informações e pautas falsas, os interagentes podem fazer com que o jornal vá atrás de fatos inexistentes, o que atrapalha a etapa de apuração jornalística. Da mesma forma, comentários ofensivos e críticas exageradas às notícias também são frequentes, vindo a incidir na circulação e no consumo da notícia. Alguns exemplos desse tipo de trollagem podem ser vistos a seguir.

Em 2009, o jornal Zero Hora lançou em seu perfil no Twitter a seguinte questão:

Aqui na redação passou um avião rasante. Assustador. Alguém mais viu alguma coisa?

Inúmeras respostas foram enviadas para o perfil, a maior parte delas apenas constatando que o ruído também foi ouvido, ou sugerindo contatar órgãos como Infraero e Defesa Civil. Porém um interagente enviou a seguinte resposta:

\section{@)zerohora eu vi um aviao em poa caindo n usina vao la}

Como alguns minutos depois constatou-se que o vôo rasante tratava-se de uma manobra militar ${ }^{\text {vii }}$, o comportamento desse interagente pode ser equiparado ao de um troll. 
No exemplo a seguir, o interagente faz um retweet acrescido de uma piada em resposta a uma mensagem postada originalmente pelo perfil do Estadão no Twitter.

tôem casaagora RT@estadao: Hoje é Dia do Estudante.Parabéns aos seguidores que estão na escola ou universidade.

Nesse exemplo, embora o comportamento do usuário não interfira na produção da notícia, representa uma típica resposta de crítica ao conteúdo veiculado pelo jornal no Twitter. Comportamento similar pode ser observado entre os seguidores de Veja no Twitter, como nos exemplos abaixo.

Vc já foi uma revista mais interessante....RT @VEJA: Depois de levar fora, Dinei esnoba Valesca Popozuda http://migre.me/5lwuN

@VEJA Isso que é pauta inútil...

Embora essas mensagens possam atrapalhar o processo jornalístico, também podem contribuir para que um determinado perfil reveja o tipo de conteúdo que vem oferecendo através do Twitter. Além disso, impõem novos desafios ao jornalismo, na medida em que acompanhar o que é dito em redes sociais passa a ser uma tarefa na organização.

A trollagem interagente-interagente, por sua vez, ocorre quando são os próprios interagentes que são afetados por mensagens postadas por interagentes. Isso pode se dar, por exemplo, quando piadas sobre acontecimentos jornalísticos são compartilhadas, sem que haja uma contextualização do fato.

Jabulani ameaça não entrar em campo se Felipe Melo for escalado

RT@usuario: 5 ministros do STF acreditam que Romeu Tuma Morreu e os outros 5 dizem q ele ainda está vivo. Vão decidir na segunda

No primeiro exemplo, acima, a piada se refere a um comentário feito pelo jogador Felipe Melo durante uma coletiva de imprensa antes da Copa em 31 de maio de 2010. Na ocasião, ele teria dito que a Jabulani, a bola da Copa, seria uma Patricinha, 
porque não gosta de apanhar ${ }^{\text {viii }}$. O comentário feito pelo jogador repercutiu na imprensa e nas redes sociais, o que deu origem a inúmeras piadas.

Já no segundo exemplo o interagente mistura dois acontecimentos que estavam sendo discutidos na mesma época, em setembro de 2010. O primeiro é uma votação do STF que teria terminado em empate devido ao fato de o Tribunal estar com apenas 10 ministros, ao invés de 11 . Diante do empate, o Tribunal adiou a votação ${ }^{\text {ix }}$. O segundo acontecimento diz respeito ao anúncio falso da morte de Romeu Tuma, dado por Folha e $U O L$ em 24 de setembro de $2010^{x}$ (que também pode ser considerado um exemplo de trollagem entre veículos, como veremos a seguir). A situação de incerteza quanto à morte deu origem ao tweet, misturando os dois acontecimentos.

Essas mensagens seriam consideradas trollagens porque exigem conhecimento prévio para que possam ser compreendidas. De qualquer modo, piadas sobre acontecimentos representam uma parcela considerável de tweets feitos por interagentes acerca de acontecimentos jornalísticos (ZAGO, 2011), o que contribui para enriquecer a circulação jornalística no Twitter, ainda que possa atrapalhar interagentes que porventura não estejam por dentro das notícias que deram origem ao tweet de humor.

Outra possibilidade de trollagem entre interagentes ocorre quando algum usuário decide espalhar uma informação falsa, como se fosse uma notícia. Para conferir efeito de verdade à falsa notícia, muitas vezes os interagentes recorrem a nomes de pessoas ou organizações renomadas, como nos exemplos a seguir:

\section{RT@g1 Bomba cai em cemitério, ainda não temos notícia de sobreviventes}

RT@realwbonner Morreu hoje aos 39 anos de idade o cantor Dinho Ouro Preto, vocalista da banda Capital Inicial.

No primeiro exemplo, o interagente tuita uma piada, mas o faz como se fosse um retweet a uma mensagem postada originalmente pelo portal $G 1$. No segundo caso, uma informação falsa é repassada, mas, para que obtenha um efeito de verdade, a mensagem é postada como se fosse um retweet a uma mensagem do apresentador do Jornal Nacional William Bonner ${ }^{\mathrm{xi}}$. 
Um terceiro tipo de trollagem possível de ocorrer é de veículos a interagentes. Esse tipo de trollagem ocorre em especial quando veículos postam informações erradas no Twitter. Isso decorre muitas vezes da velocidade possibilitada pela ferramenta, que torna possível tuitar tão logo se fique sabendo de um fato. Entretanto, representa falhas na apuração jornalística, na medida em que envolve a postagem de informações não verificadas adequadamente. Esse tipo de trollagem está especialmente ligada às de tipo interagentes-interagentes (na medida em que um veículo pode tuitar como fato alguma informação originada como boato) e veículos-veículos (pois uma informação errônea divulgada por um veículo pode vir a pautar outros veículos).

Um exemplo pode ser dado com o anúncio falso da morte de Romeu Tuma, já mencionado acima. Folha e Uol colocaram em seus sites uma notícia sobre a morte do senador em 24 de setembro de 2010 e também postaram no Twitter a informação. A partir dessa notícia, outros jornais, como $O$ Globo e Correio de Uberlândia, também tuitaram e noticiaram a informação de que o senador havia morrido, numa forma de trollagem veículos-veículos. Pouco tempo depois, a informação foi desmentida.

O caso se tornou mais emblemático quando, um mês depois, em 26 de outubro de 2010, o senador Romeu Tuma veio a falecer. Na ocasião, interagentes tuitaram sobre o caso, buscando relacionar com o acontecimento anterior.

Senador Romeu Tuma faleceu, informou a UOL. Será que dessa vez é verdade?

Senador Romeu Tuma morreu, como a Folha já tinha antecipado há algumas semanas.

Seja na forma de interagentes a veículos, interagentes a interagentes, veículos a interagentes ou veículos a veículos, identificar os tipos de trollagens mais comuns podem ajudar a aprender a lidar com elas. Enquanto no caso de compartilhamento de informações falsas é possível usar o mesmo canal (Twitter), para desmentir a informação (e provavelmente com a mesma velocidade de espalhamento), nos casos em que o interagente critica gratuitamente a notícia ou a organização, ou em que envia contribuições com o intuito de prejudicar o veículo, responder ao interagente (ou "alimentar o troll", na linguagem da cibercultura) poderia significar uma troca de 
mensagens infindável e uma visibilidade desnecessária ao ato buscando desestabilizar a discussão. Mesmo assim, ao menos no contexto do processo jornalístico no Twitter, nem sempre um troll é algo negativo a ser combatido. Críticas de um troll podem ajudar um veículo a aprimorar seu posicionamento, ao passo que uma trollagem pode levar à produção de uma nova notícia.

\section{Apontamentos finais}

O trabalho procurou discutir a presença de trolls no contexto das etapas do processo jornalístico no Twitter. Quatro caminhos possíveis para as trollagens foram identificados e ilustrados: de interagentes a veículos, de interagentes a interagentes, de veículos a interagentes e de veículos a veículos.

Os exemplos recolhidos reforçam a ideia de um papel emergente para o jornalista num contexto de jornalismo interativo e conversacional (HEINRICH, 2011). Mais do que estar nas redes sociais, é preciso também estar atento ao que circula através delas. Informações falsas podem ser postas em circulação por indivíduos mal intencionados, do mesmo modo em que a ânsia por publicar o quanto antes pode levar os veículos a publicarem informações mal apuradas.

Por se tratar de um espaço público mediado (BOYD, 2007) em que cada interagente pode postar livremente em seu próprio perfil, os sites de redes sociais se constituem em ambientes que fogem ao controle das organizações. Diferentemente dos comentários a uma notícia no site do jornal, em que se pode optar por moderá-los previamente, o que é dito num site de rede social permanece lá, podendo ser acessado por outros usuários. Por isso a existência de trolls deve ser reconhecida, em especial para que se possa aprender a lidar com eles.

Por outro lado, como diz a máxima da internet, não se deve alimentar os trolls. Ao responder publicamente uma mensagem ofensiva, pode-se estar dando uma visibilidade desnecessária à fala do troll.

A existência de trolls é inerente a qualquer tipo de ambiente interativo online. Sempre que houver um grupo organizado em torno de um tema, haverá alguém com uma postura disruptiva. Assim, um caminho possível a ser adotado é o de reconhecer a existência dos trolls no jornalismo também no contexto dos sites de redes sociais, para a 
partir daí pensar em estratégias para lidar com eles e evitar que interfiram no processo jornalístico como um todo.

\section{Referências}

AMARAL, A.; QUADROS, C. Agruras do Blog: o jornalismo cor-de-rosa no ciberespaço? Razón y Palabra, n.53, 2006. Disponível em http://www.razonypalabra.org.mx/anteriores/n53/amaralquadros.html. Acesso em 14 mar. 2012.

BELOCHIO, V. Jornalismo colaborativo em redes digitais: estratégia comunicacional no ciberespaço. O caso de Zero Hora.com. Dissertação (Mestrado em Comunicação Midiática). Universidade Federal de Santa Maria. Santa Maria, 2009.

BERGSTROM, K. "Don't feed the troll": Shutting down debate about community expectations on Reddit.com. First Monday, v.16, n.8, 2011. Disponível em http://firstmonday.org/htbin/cgiwrap/bin/ojs/index.php/fm/article/view/3498/3029. Acesso em 14 mar. 2012.

BOYD, D.; ELLISON, N. Social network sites: Definition, history and scholarship. Journal of Computer-Mediated Communication. v. 13, n. 1, 2007. Disponível em http://jcmc.indiana.edu/vol13/issue1/boyd.ellison.html. Acesso em: 20 jan. 2009.

BOYD, D. Social Network Sites: Public, Private, or What? Knowledge Tree, n.13, maio 2007. Disponível em http://kt.flexiblelearning.net.au/tkt2007/?page_id=28. Acesso em: 13 jul. 2010.

DONATH, J. Identity and Deception in the Virtual Community. In: KOLLOCK, P.; SMITH, M. (Orgs.) Communities in Cyberspace. Londres: Routledge, 1999.

FONTANELLA, F. Nós somos Anonymous: anonimato, trolls e subcultura dos imageboards. In: XXXIII Congresso Brasileiro de Ciências da Comunicação, Caxias do Sul, 2010. Anais... Caxias do Sul, RS, 2010.

HEINRICH, A. Network Journalism. New York: Routledge, 2011.

KEEN, A. O Culto do Amador: como MySpace, YouTube e a pirataria digital estão destruindo nossa economia, cultura e valores. Rio de Janeiro: Jorge Zahar Ed., 2009.

MACHADO, E.; PALACIOS, M. Um modelo híbrido de pesquisa: a metodologia aplicada pelo GJOL. In: LAGO, C.; BENETTI, M. (Orgs.). Metodogia de pesquisa em jornalismo. Petrópolis: Vozes, 2007, p.199-222.

MIELNICZUK, L. Jornalismo na Web: uma contribuição para o estudo do formato da notícia na escrita hipertextual. Tese (Doutorado em Comunicação e Culturas Contemporâneas). Universidade Federal da Bahia. Salvador, 2003. 
PALACIOS, M. Ruptura, Continuidade e Potencialização no Jornalismo Online: o lugar da memória. In: MACHADO, E.; PALACIOS, M. (Orgs.) Modelos de Jornalismo Digital. Salvador: Editora Calandra, 2003.

RECUERO, R. Redes Sociais na Internet. Porto Alegre: Sulina, 2009.

TRÄSEL, M. A pluralização no webjornalismo participativo: uma análise das intervenções no Wikinews e no Kuro5hin. Dissertação (Mestrado em Comunicação e Informação). Universidade Federal do Rio Grande do Sul. Porto Alegre, 2007.

ZAGO, G. Recirculação jornalística no Twitter: filtro e comentário de notícias por interagentes como uma forma de potencialização da circulação. Dissertação (Mestrado em Comunicação e Informação). Universidade Federal do Rio Grande do Sul. Porto Alegre, 2011. 
${ }^{\mathrm{i}}$ Uma das mais antigas redes de computador ainda em uso, constituída por fóruns de discussão de texto organizados por tópicos.

ii Tradução de: "Trolling is a game about identity deception, albeit one that is played without the consent of most of the players" (DONATH, 1999, online).

iii Tradução de: "Responding to a troll is very tempting, especially since these posts are designed to incite" (DONATH, 1999, online).

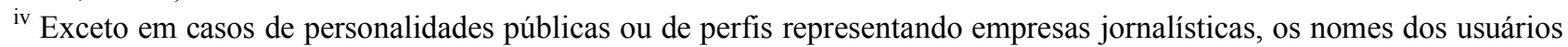
que aparecem nos retweets foram substituídos pela palavra usuário, seguida de um número de identificação. Os tweets foram anonimizados para este trabalho, segundo as recomendações de ética em pesquisa da Association of Internet Researchers (http://aoir.org/reports/ethics.pdf), mantendo-se a grafia original das mensagens.

v Tradução de "The facilitation of conversations with users and the inclusion of interactivity features is becoming an inevitable part of journalistic production in the evolving network journalism sphere and how to manage these conversations online is just one emerging task journalistic organizations have to deal with" (HEINRICH, 2011, p. 179). vi Tradução de: "At least in the Indymedia world, interactivity means dealing with trolls! Dealing with disrupters" (HEINRICH, 2011, p. 179).

vii “Avião com voo rasante na Capital seria da Força Aérea Brasileira”, Zero Hora, 15 nov. 2009. Disponível em $<$ http://zerohora.clicrbs.com.br/rs/noticia/2009/11/aviao-com-voo-rasante-na-capital-seria-da-forca-aerea-brasileira2718282.html>. Acesso em 14 mar. 2012.

viii "Felipe Melo muda nome da bola da Copa. Jabulani agora é 'Patricinha"”, Globo Esporte, 31 maio 2010. Disponível em $<$ http://globoesporte.globo.com/futebol/selecao-brasileira/noticia/2010/05/felipe-melo-muda-nome-da-jabulanibola-da-copa-agora-e-patricinha.html>. Acesso em 14 mar. 2012.

ix “Após empate, STF decide suspender julgamento sobre ficha limpa”, G1, 24 set. 2010. Disponível em $<$ http://g1.globo.com/especiais/eleicoes-2010/noticia/2010/09/apos-empate-stf-decide-suspender-julgamento-sobreficha-limpa.html>. Acesso em 14 mar. 2012.

x "Folha.com errou: senador Romeu Tuma não morreu e permanece internado", Folha.com, 24 set. 2010. Disponível em $<$ http://www1.folha.uol.com.br/poder/804535-folhacom-errou-senador-romeu-tuma-nao-morreu-e-permaneceinternado.shtml >. Acesso em 04 jan. 2011

xi "Twitter espalha falsa notícia sobre morte de Dinho", R7, 27 nov. 2009. Disponível em $<\mathrm{http}$ //entretenimento.r7.com/musica/noticias/twitter-espalha-noticia-falsa-sobre-morte-de-dinho-20091127.html >. Acesso em 14 mar. 2012. 